\title{
A Study on Creativity of University Students
}

\author{
Yohei Hara *, Hiroyuki Ono *
}

\begin{abstract}
Daily innovation and improvement activities within the company are important for a company to carry out sustainable management. In addition, in-house innovation and improvement activities are also required to be efficient, such as shortening the time required to solve problems. Therefore, it is important for employees to discover issues, execute, and teamwork. Among them, creativity is especially required. In terms of creativity, many researchers have suggested the importance of fostering creativity in childhood and youth. Therefore, in this study, we focus on youth students, collect cases of daily successful experiences from childhood to youth based on interview surveys, analyze them, and clarify their characteristics.
\end{abstract}

Keywords: Creativity; Equation of Creation; K-Type classification; Sense of Distance

\section{Introduction}

In the information society, in order to carry out the sustainable management of companies, it is important improvement activities and day-to-day innovation in the enterprise. In addition, in-house innovation and improvement activities are also required to be efficient, such as shortening the time required to solve problems. Therefore, it is important for employees to discover issues, execute, and teamwork. In particular, the Ministry of Economy, Trade and Industry has summarized it as "Basic ability to work in society" as an ability element required of young employees [1]-[3]. Basic ability to work in society is composed of 3 abilities and 12 elements. The first is "the power to step forward (Action)", which indicates area such as motivation necessary for living a social life. Independence, working ability, and execution ability are mentioned as necessary elements here. Next, "the ability to work in a team (Teamwork)", in a narrow sense, means to utilize oneself in the organization based on the communication ability in the organization. In a broad sense, it means the ability to utilize oneself in society based on communication skills in society rather than an organization. The necessary elements here include transmission power, flexibility, and stress control power. Finally, "thinking power (Thinking)" is shown as an important matter for re-recognizing the thoughts that people should enjoy in their lives. The necessary elements here are problem-finding ability, planning ability, and creativity.

\footnotetext{
* Chiba Institute of Technology, Chiba, Japan
} 
The Japan Business Federation has summarized it as "Three required forces" [4][5] that industry is demanding for the next generation in "Proposals for fostering the next generation to survive the 21 st century". The first is "Aspiration and Power", which is defined as the ability to work on things with a sense of mission, with norms as a member of society. The elements that make up "Aspiration and Power" include humanity, sociality, and a sense of responsibility. Next, "Activity" defines the ability to achieve goals while overcoming difficulties through information gathering, negotiations and coordination. The elements that make up "Activity" include execution ability, communication ability, and ability to understand different cultures. Finally, "Intelligence" is defined as the ability to explore and think deeply about things. The elements that make up "Intelligence" include basic academic ability, logical thinking ability, and originality.

Creation is one of the common things in the "Basic powers of working people" compiled by the Ministry of Economy, Trade and Industry and the "Three required forces" compiled by the Japan Business Federation. Therefore, it is considered that the necessity of creativity is shown in order to live in society. As for creativity, if we think that small daily ingenuity and KAIZEN activity are also creativity, everyone is doing creativity every day. Therefore, how that systematically summarizes creation process flow creation is performed, considering that it would be able to efficiently daily ingenuity and KAIZEN activity by training.

Creation is defined as "production of new information" and assumed that a new information element $(\mathrm{N})$ is produced by the new combination of two known information elements (A and $\mathrm{B}$ ). The process is described as $\mathrm{A} * \mathrm{~B}=\mathrm{N}$ and it is called "The equation of creation" [6]. Over 900 cases collected from various fields such as business, design, science $\&$ technology have been analyzed using the equation of creation to A, B, N. During this process we found another important element $\mathrm{K}$ and it has been added to the parameter. Element $\mathrm{K}$ describes the clue for the creator to start the creative process. The process is described as $\mathrm{K} \rightarrow \mathrm{A} * \mathrm{~B}=\mathrm{N}$ and it is called "The creative process".

In order to enhance the creativity, it has been made a variety of research relates to creativity education of childhood and youth [7]. Professor EP Torrance, a psychologist and pedagogue in the United States, created the Torrance Test of Creative Thinking (TTCT) to measure creative thinking ability, calculated the creative index, and used the result as CQ (Creativity Quotient). Torrance shows the relationship between IQ (Intelligence Quotient) and CQ, and uses CQ to show the usefulness of creativity education from childhood by summarizing decades of lifelong achievements for subjects with high CQ [8]. For education on creativity, starting with the scientific research a variety of initiatives around the world have been made for creativity by Guildford that took place from 1950 [9]. Therefore, it is important to educate creativity to clarify whether there is a difference between the creativity that takes place by youth and the creativity process of creativity in society. It focused on what kind of creation students had before going out into society.

\section{Purpose of Study}

As the information society progresses, the elements that companies demand from relatively young employees are summarized by the Ministry of Economy, Trade and Industry's "Basic ability to work in society" and the Japan Business Federation's "Three required forces". There is creativity in these two common points. How to secure human resources who can create is important for sustainable management in a company. In creative research, many researchers, such as Torrance [8] and Tsukamoto [10], have suggested the importance of fostering creativity in childhood and youth. 
Therefore, in creating a creative education program, this research focuses on students and aims at what characteristics they have about creation.

\section{Research Methods}

Based on the results of interviews with 98 our university students (85 men and 13 women in the 3rd to 4th grades) about successful experiences such as studying, part-time job and play from childhood to the present, it will analyze using the creative process. Each information element (K, A, B and N) obtained from the creative process is classified into "K-Type classification", "SD: Sense of Distance", and "A*B combination type classification". As a result, it will confirm whether there is a new classification and summarize the characteristics of creation.

\section{A. K-Type classification}

(1) $K=$ A type

This type describes the creative case where A can be specified from K. Most of the cases analyzed in this study are ascribed to this type. Our way of thinking is usually following this process, "First $\mathrm{K}$ fixes A, then search B".

(2) $K=N$ type

This type means that the concept of $\mathrm{N}$ is deduced from $\mathrm{K}$. Our way of thinking is usually following this process, "First K gives the concept of N. After that it fixes A, then search B".

(3) $K \neq A$, N type

This type means $\mathrm{K}$ is not directly related to A nor $\mathrm{N}$.

For the case of " $\mathrm{K}=\mathrm{A}$ type", the relationship between known information $\mathrm{A}$ and known information $\mathrm{B}$ is analyzed using "SD" and " $\mathrm{A} * \mathrm{~B}$ combination type classification".

\section{B. SD: Sense of Distance and $A^{*} B$ combination type classification}

"SD" is defined as the ease of searching for known information B after identifying known information A. In other words, it is thought that creation is done in the individual's mind, and it can be classified by the search method of known information B. SD that corresponds to "Inside information (Knowledge)" is defined as "extremely near" area by SD is Awareness area. SD that corresponds to "Look-up" is defined as "near", area by SD is Selection area. SD that corresponds to exploratory search such as "Learn" and "Investigate" is defined as "far", area by SD is Inspiration area. SD is divided into three stages (Table 1).

Table 1: SD and SD area

\begin{tabular}{|c|c|c|}
\hline How to search & SD & Area by SD \\
\hline Inside information (Knowledge) & Extremely Near & Awareness area \\
\hline Look-up & Close & Selection area \\
\hline Learn, Investigate & Far & Inspiration area \\
\hline
\end{tabular}

"A*B combination type classification" systematically summarizes the search method of known information B into 3 groups and 18 classifications. 


\section{Results and Discussion}

In 141 target cases, based on the equation of creation, it was decomposed into four pieces of information: trigger $\mathrm{K}$, known information $\mathrm{A}$, known information $\mathrm{B}$, and new information $\mathrm{N}$. The four decomposed information is summarized for the $\mathrm{K}$ classification, which shows the relationship with other information from the trigger $\mathrm{K}$. As a result of $\mathrm{K}$ classification, 133 cases of $\mathrm{K}=\mathrm{A}$ type, 3 cases of $\mathrm{K}=\mathrm{N}$ type, and 5 cases of $\mathrm{K} \neq \mathrm{A}, \mathrm{N}$ type were obtained for 141 target cases. Many $\mathrm{K}=\mathrm{A}$ types were seen. From this, it is considered that $\mathrm{K}=\mathrm{A}$ type is a basic pattern for creation. Therefore, the basic form of the creative process, which shows the flow of creation, consider that "known information A" is specified from "the trigger K", "known information B" to be combined is searched, specified, and combined, and "new information N" is born.".

However, as a result of investigating the relationship between two important known information in creation, SD determines the relationship between known information A and known information $\mathrm{B}$ for 133 cases classified as $\mathrm{K}=\mathrm{A}$ type. Analysis was performed using the region and $\mathrm{A} * \mathrm{~B}$ binding type classification. Table 2 shows the results of the area by SD.

Table 2: SD area

\begin{tabular}{|l|r|}
\hline \multicolumn{1}{|c|}{ Area by SD } & Number of cases \\
\hline Awareness area & 49 \\
\hline Selection area & 77 \\
\hline Inspiration area & 7 \\
\hline Total & 133 \\
\hline
\end{tabular}

From the result of the area by SD, it can be seen that more searches such as "reference" were performed than the search of known information $B$ by internal information.

Further, the $\mathrm{A}^{*} \mathrm{~B}$ combination type classification is a classification focusing on the search method of the known information $B$ to be searched after the known information A is specified. The results of $A * B$ combination type classification are shown in Table 3 and Figure 1.

Table 3: $\mathrm{A} * \mathrm{~B}$ combination type classification

\begin{tabular}{|c|c|c|c|}
\hline A*B Combination type & Number of cases & A*B Combination type & Number of cases \\
\hline Introduced type & 98 & Expanded & 36 \\
\hline Imitation type & 12 & Application development type & 3 \\
\hline Knowledge and experience type & 49 & Replacement type & 3 \\
\hline Customary type & 8 & Substitute type & 20 \\
\hline Additional function type & 21 & Sensibility type & 10 \\
\hline Associative type & 7 & Total & 138 \\
\hline Functional application type & 0 & & \\
\hline Correlated & 1 & & \\
\hline Simulated & 0 & & \\
\hline Hybrid & 4 & & \\
\hline Experimental type & 2 & & \\
\hline Scaling type & 1 & & \\
\hline Choice-intensive & 0 & & \\
\hline The combination of the machine & 0 & & \\
\hline Common sense destruction type & 1 & & \\
\hline Integrated & 0 & & \\
\hline
\end{tabular}




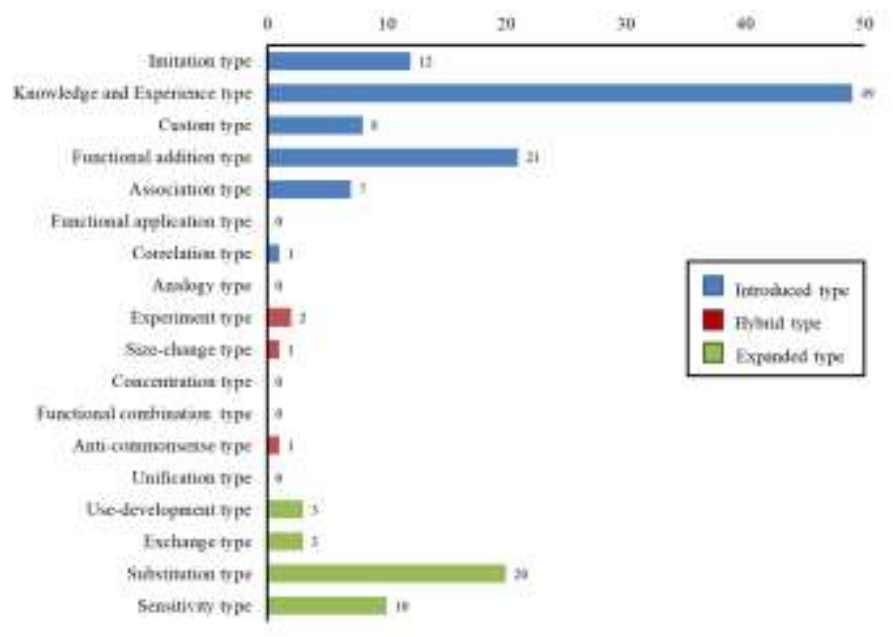

Figure 1: $\mathrm{A} * \mathrm{~B}$ combination type classification

From the results of "A*B combination type classification", there were many cases of "Knowledge and experience type" and many cases of "Sensibility type".

Table 4 and Figure 2 show the "Area by SD" and "A*B combination type classification".

Table 4: Area by SD and A*B combination type classification

\begin{tabular}{|c|c|c|c|c|c|}
\hline Areas by SD & $\mathrm{A} * \mathrm{~B}$ Combination type & Number of cases & Areas by $\mathrm{SD}$ & $\mathrm{A} * \mathrm{~B}$ Combination type & Number of cases \\
\hline \multirow{21}{*}{$\begin{array}{c}\text { Awareness area } \\
49 \text { 件 }\end{array}$} & Introduction type & 41 & \multirow{21}{*}{$\begin{array}{l}\text { Inspiration area } \\
\quad 7 \text { 件 }\end{array}$} & Introduction type & 1 \\
\hline & Imitation type & 4 & & Imitation type & 0 \\
\hline & Knowledge and Experience type & 30 & & Knowledge and Experience type & 0 \\
\hline & Custom type & 6 & & Custom type & 0 \\
\hline & Functional addition type & 1 & & Functional addition type & 0 \\
\hline & Association type & 0 & & Association type & 0 \\
\hline & Functional application type & 0 & & Functional application type & 0 \\
\hline & Correlation type & 0 & & Correlation type & 1 \\
\hline & Analogy type & 0 & & Analogy type & 0 \\
\hline & Hybrid type & 2 & & Hybrid type & 1 \\
\hline & Experiment type & 1 & & Experiment type & 0 \\
\hline & Size-change type & 1 & & Size-change type & 0 \\
\hline & Concentration type & 0 & & Concentration type & 0 \\
\hline & Functional combination type & 0 & & Functional combination type & 0 \\
\hline & Anti-commonsense type & 0 & & Anti-commonsense type & 1 \\
\hline & Unification type & 0 & & Unification type & 0 \\
\hline & Extension type & 6 & & Extension type & 5 \\
\hline & Use-development type & 0 & & Use-development type & 0 \\
\hline & Exchange type & 0 & & Exchange type & 1 \\
\hline & Substitution type & 6 & & Substitution type & 0 \\
\hline & Sensitivity type & 0 & & \begin{tabular}{|l|} 
Sensitivity type \\
\end{tabular} & 4 \\
\hline \multirow{21}{*}{$\begin{array}{c}\text { Selection area } \\
\quad 77 \text { 件 }\end{array}$} & Introduction type & 56 & & \multirow[t]{21}{*}{ Total } & \multirow[t]{21}{*}{138} \\
\hline & Imitation type & 8 & & & \\
\hline & Knowledge and Experience type & 19 & & & \\
\hline & Custom type & 7 & & & \\
\hline & Functional addition type & 20 & & & \\
\hline & Association type & 7 & & & \\
\hline & Functional application type & 0 & & & \\
\hline & Correlation type & 0 & & & \\
\hline & Analogy type & 0 & & & \\
\hline & Hybrid type & 1 & & & \\
\hline & Experiment type & 1 & & & \\
\hline & Size-change type & 0 & & & \\
\hline & Concentration type & 0 & & & \\
\hline & Functional combination type & 0 & & & \\
\hline & Anti-commonsense type & 0 & & & \\
\hline & Unification type & 0 & & & \\
\hline & Extension type & 25 & & & \\
\hline & Use-development type & 3 & & & \\
\hline & Exchange type & 7 & & & \\
\hline & Substitution type & 14 & & & \\
\hline & Sensitivity type & & & & \\
\hline
\end{tabular}




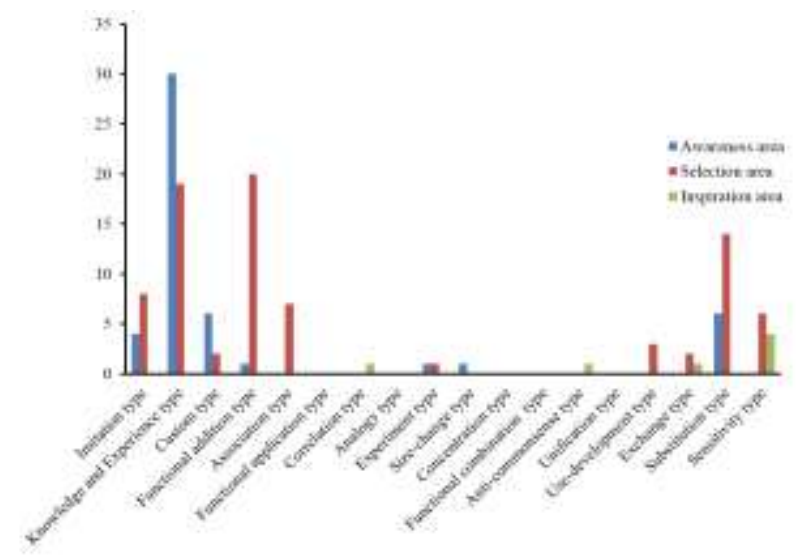

Figure 2: Area by $\mathrm{SD}$ and $\mathrm{A} * \mathrm{~B}$ combination type classification

From the above results, it can be seen that, as a whole, $\mathrm{A} * \mathrm{~B}$ combination classification is performed in familiar information area such as "Knowledge and experience type", "Additional function type", and "Substitute type".

The 141 creative cases collected were classified according to the creative period of "Childhood", "Boyhood", and "Youth". For each period, the age group used by the Ministry of Health, Labor and Welfare was used. "Childhood" is 0-5 years old. "Boyhood" is 6-14 years old. "Youth" is 15-24 years old. The number of cases collected during the creative period was 1 in childhood, 43 in boyhood, and 97 in youth. Table 5 and Figure 3 summarize the K-Type classification performed during each creation period.

Table 5: K-type classification performed during each creation period

\begin{tabular}{|c|c|c|c|c|c|}
\hline Creation Period & $\begin{array}{l}\text { K-Type } \\
\text { classification }\end{array}$ & Number of cases & Creation Period & $\begin{array}{l}\text { K-Type } \\
\text { classification }\end{array}$ & Number of cases \\
\hline \multirow{4}{*}{ Childhood } & $\mathrm{K}=\mathrm{A}$ type & 1 & \multirow[t]{4}{*}{ Youth } & $\mathrm{K}=\mathrm{A}$ type & 93 \\
\hline & $\mathrm{K}=\mathrm{N}$ type & 0 & & $\mathrm{~K}=\mathrm{N}$ type & 3 \\
\hline & $\mathrm{K} \neq \mathrm{A}, \mathrm{N}$ type & 0 & & $\mathrm{~K} \neq \mathrm{A}, \mathrm{N}$ type & 1 \\
\hline & Total & 1 & & Total & 97 \\
\hline \multirow{4}{*}{ Boyhood } & $\mathrm{K}=\mathrm{A}$ type & 39 & & Total & 141 \\
\hline & $\mathrm{K}=\mathrm{N}$ type & 0 & & & \\
\hline & $\mathrm{K} \neq \mathrm{A}, \mathrm{N}$ type & 4 & & & \\
\hline & Total & 43 & & & \\
\hline
\end{tabular}

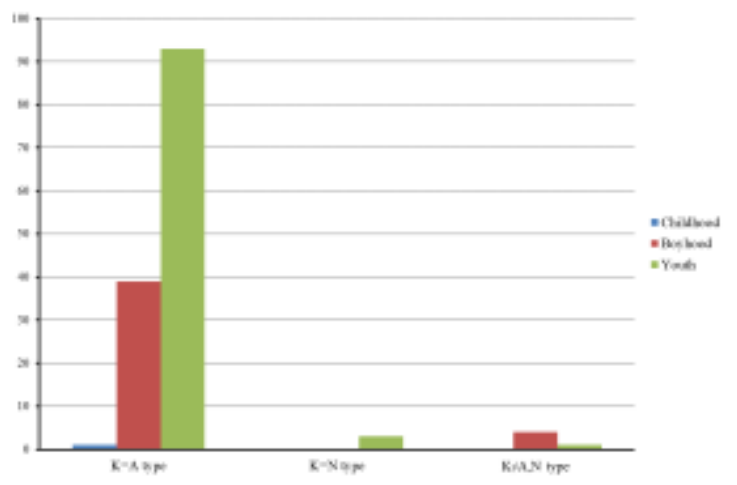

Figure 3: K-type classification performed during each creation period

From the above results, there were many $\mathrm{K}=\mathrm{A}$ type in each creation period, and in boyhood, there was no creation to come up with a concept like $\mathrm{K}=\mathrm{N}$ type. The proportion of cases of $\mathrm{K} \neq \mathrm{A}$ and $\mathrm{N}$ types was higher than in other periods. 
In youth, there was a creation that came up with a concept like $\mathrm{K}=\mathrm{N}$ type. In the $\mathrm{K}$-Type classification at each creation period collected in this study, there is a tendency for more cases to come up with concepts such as $\mathrm{K}=\mathrm{N}$ type as the age increases, while known information for the purpose of having fun from images etc. happens to be. The classification of $\mathrm{K} \neq \mathrm{A}$ and $\mathrm{N}$ types that bind to is reduced. Next, Table 6 and Figure 4 summarize the area in $\mathrm{SD}$ at each creation period.

Table 6: The area in SD at each creation period

\begin{tabular}{|c|c|c|c|c|c|}
\hline $\begin{array}{c}\text { Creation } \\
\text { Period }\end{array}$ & Area by SD & Number of cases & $\begin{array}{l}\text { Creation } \\
\text { Period }\end{array}$ & Area by SD & Number of cases \\
\hline \multirow{4}{*}{ Childhood } & Awareness area & 0 & \multirow{4}{*}{ Youth } & Awareness area & 38 \\
\hline & Selection area & 1 & & Selection area & 51 \\
\hline & Inspiration area & 0 & & Inspiration area & 4 \\
\hline & Total & 1 & & Total & 93 \\
\hline \multirow{4}{*}{ Boyhood } & Awareness area & 11 & & Total & 133 \\
\hline & Selection area & 25 & & & \\
\hline & Inspiration area & 3 & & & \\
\hline & Total & 39 & & & \\
\hline
\end{tabular}

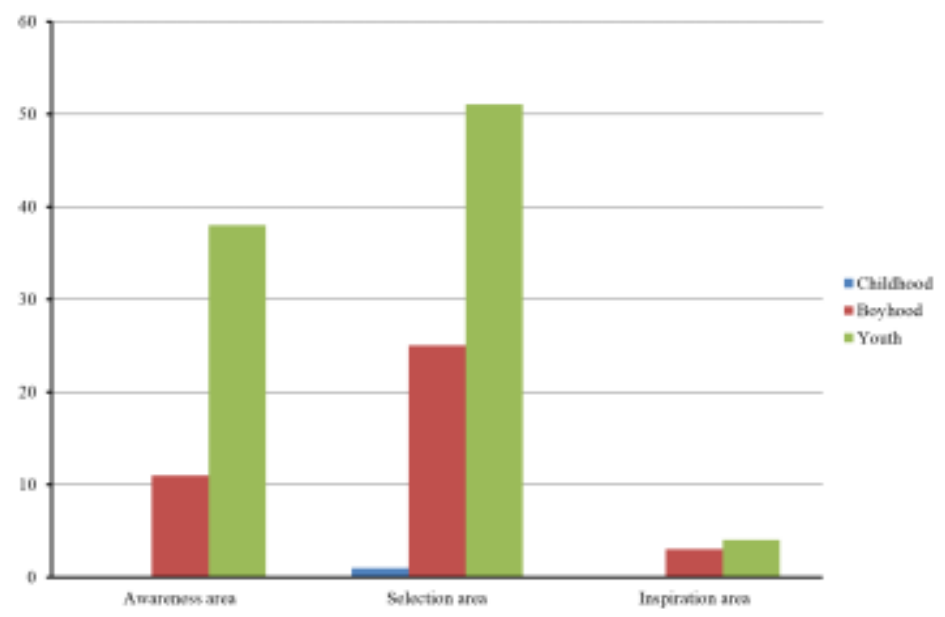

Figure 4: The area in SD at each creation period

In addition, the regions in $\mathrm{SD}$ and the $\mathrm{A} * \mathrm{~B}$ combination type classification at each creation period are summarized in Figure 5,6, 7, and Table 7.

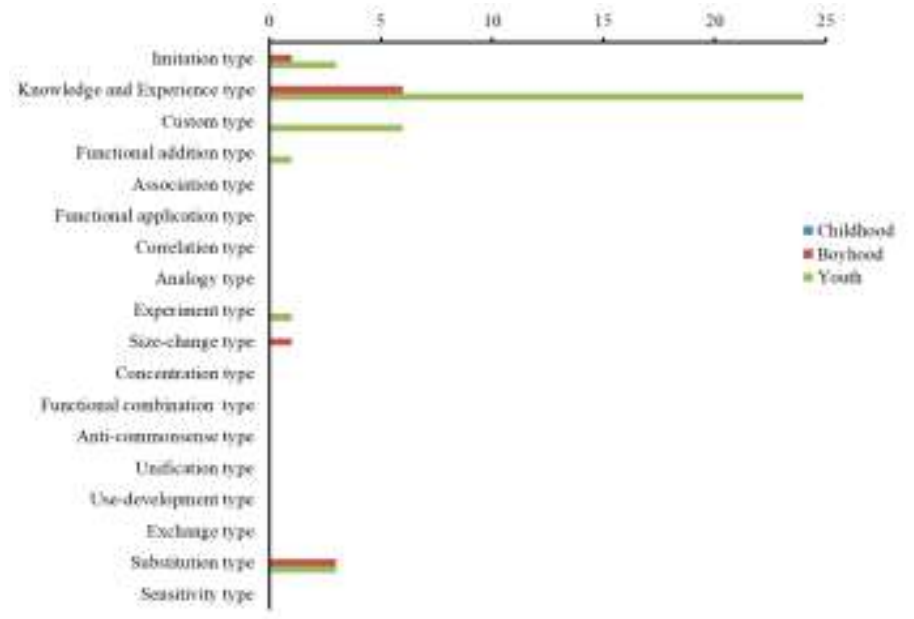

Figure 5: Awareness area and $\mathrm{A} * \mathrm{~B}$ combination type classification 


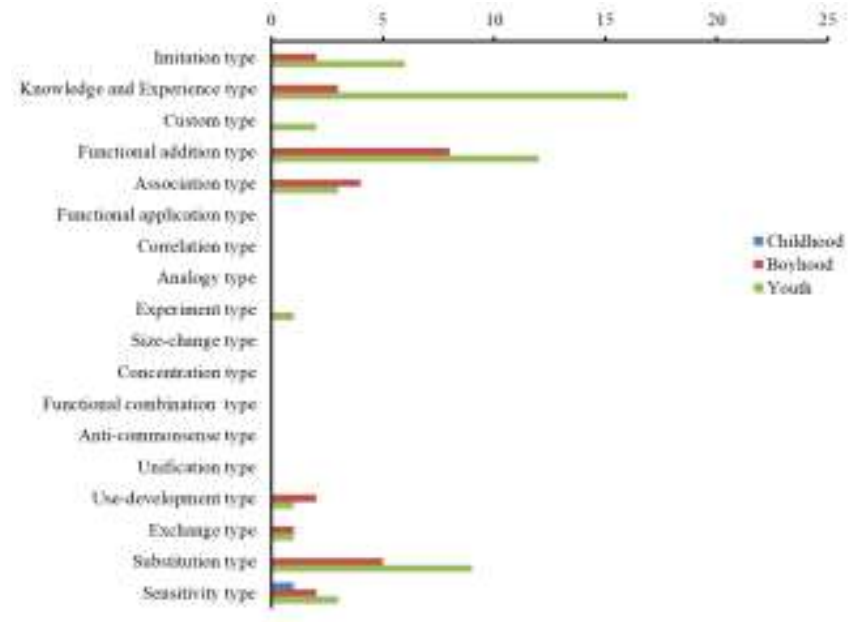

Figure 6: Selection area and $\mathrm{A} * \mathrm{~B}$ combination type classification

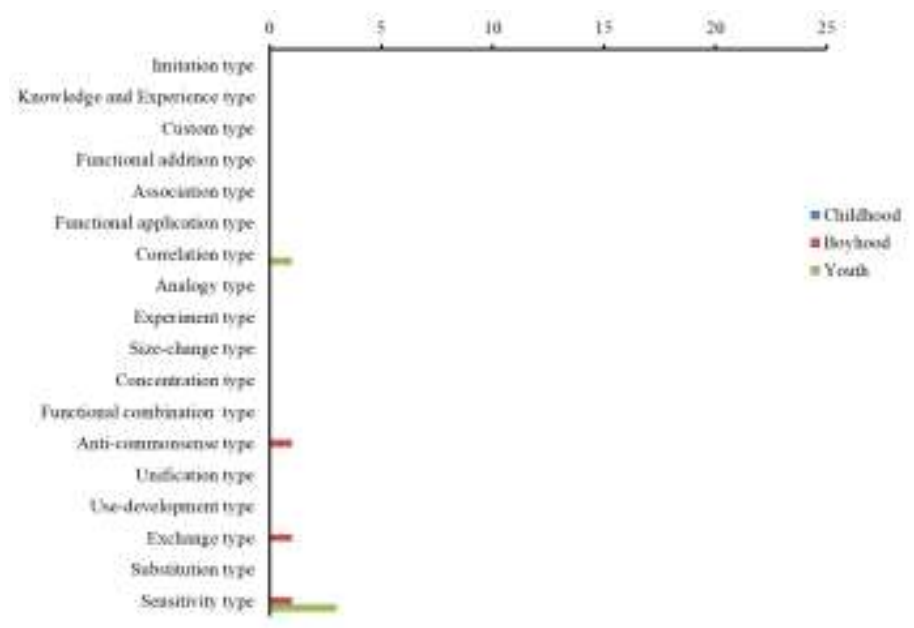

Figure 7: Inspiration area and $\mathrm{A} * \mathrm{~B}$ combination type classification

Table 7: SD and the $\mathrm{A} * \mathrm{~B}$ combination type classification at each creation period

\begin{tabular}{|c|c|c|c|c|c|c|c|}
\hline Creation Period & Areas by SD & $\mathrm{A} * \mathrm{~B}$ Combination type & Number of cases & \begin{tabular}{|l|} 
Creation Period \\
\end{tabular} & Areas by SD & A*B Combination type & Number of cases \\
\hline \multirow{10}{*}{ Childhood } & \multirow{3}{*}{ Awareness area } & Introduction type & 0 & & \multirow{9}{*}{ Awareness area } & Introduction type & 34 \\
\hline & & Hybrid type & 0 & & & Imitation type & \\
\hline & & Extension type & 0 & & & Knowledge and Experience type & 24 \\
\hline & \multirow{4}{*}{ Selection area } & Introduction type & 0 & & & Custom type & \\
\hline & & Hybrid type & 0 & & & \begin{tabular}{|l} 
Functional addition type \\
\end{tabular} & \\
\hline & & Extension type & 1 & & & Hybrid type & \\
\hline & & \begin{tabular}{|l|l} 
& Sensitivity type \\
\end{tabular} & & & & Experiment type & \\
\hline & \multirow{3}{*}{ Inspiration area } & Introduction type & 0 & & & Extension type & \\
\hline & & Hybrid type & 0 & & & Substitution type & \\
\hline & & Extension type & 0 & \multirow{18}{*}{$\begin{array}{l}\frac{3}{3} \\
\frac{3}{7} \\
\frac{2}{3} \\
\frac{3}{8} \\
\frac{8}{4} \\
\frac{1}{1} \\
\frac{1}{2} \\
\frac{1}{1} \\
\frac{1}{2}\end{array}$} & \multirow{13}{*}{ Selection area } & Introduction type & 39 \\
\hline \multirow{24}{*}{ Boyhood } & \multirow{7}{*}{ Awareness area } & Introduction type & 7 & & & Imitation type & 6 \\
\hline & & Imitation type & 1 & & & Knowledge and Experience type & 16 \\
\hline & & Knowledge and Experience type & 6 & & & Custom type & 2 \\
\hline & & \begin{tabular}{|l|} 
Hybrid type \\
\end{tabular} & 1 & & & \begin{tabular}{|l} 
Functional addition type \\
\end{tabular} & 12 \\
\hline & & \begin{tabular}{|l|l} 
Size-change type \\
\end{tabular} & & & & \begin{tabular}{|l|} 
Association type \\
\end{tabular} & \\
\hline & & Extension type & 3 & & & Hybrid type & \\
\hline & & \begin{tabular}{|l|l} 
Substitution type \\
\end{tabular} & 3 & & & \begin{tabular}{|l|} 
Experiment type \\
\end{tabular} & \\
\hline & & Introduction type & 17 & & & Extension type & 14 \\
\hline & & Imitation type & & & & Use-development type & \\
\hline & & Knowledge and Experience type & 3 & & & \begin{tabular}{|l|} 
Exchange type \\
\end{tabular} & \\
\hline & & \begin{tabular}{|l} 
Functional addition type \\
\end{tabular} & 8 & & & Substitution type & \\
\hline & & \begin{tabular}{|l} 
Association type \\
\end{tabular} & & & & Sensitivity type & \\
\hline & Selection area & Hybrid type & 0 & & & Introduction type & \\
\hline & & Extension type & 10 & & & \begin{tabular}{l|l} 
Correlation type \\
\end{tabular} & \\
\hline & & Use-development type & 2 & & Inspiration area & \begin{tabular}{|l} 
Hybrid type \\
\end{tabular} & \\
\hline & & Exchange type & & & & \begin{tabular}{|l} 
Extension type \\
\end{tabular} & \\
\hline & & Substitution type & & & & Sensitivity type & \\
\hline & & Sensitivity type & 2 & & & Total & 138 \\
\hline & & Introduction type & 0 & & & & \\
\hline & & Hybrid type & & & & & \\
\hline & & Anti-commonsense type & & & & & \\
\hline & Inspriation area & Extension type & & & & & \\
\hline & & \begin{tabular}{|l|l} 
Exchange type \\
\end{tabular} & & & & & \\
\hline & & Sensitivity type & & & & & \\
\hline
\end{tabular}


From the above results, it can be seen that many "knowledge and experience type" are seen in the area of awareness in both boyhood and youth, and that information groups that are familiar to them are combined. In the selection area, "additional functions" were often seen in both youth and youth, however in boyhood, "associative type" was often seen, whereas in youth, "knowledge and experience type" was seen. There was a lot of creation. As they grew up from boyhood to youth, there was not much difference in familiar creation as in the area of awareness, however in the area of selection, there was a tendency to create based on knowledge and experience.

\section{Conclusions}

$\mathrm{N}$ In this study, the creative cases obtained by the hearing survey were classified into four pieces of information (K, A, B, and $\mathrm{N}$ ) based on the creative process. The relationship of each information was classified into "K-Type classification", "SD: Sense of Distance", and "A*B combination type classification", and the contents were confirmed. In addition, in the $A * B$ combination type classification, many "knowledge and experience type" were found. As a result of classifying into "K-Type classification", "SD: Sense of Distance", and "A*B combination type classification", no new classification was found in each classification.

The results of classifying the cases collected in this study into childhood, boyhood, youth and creation period. As a result of the K-Type classification, no creative case showing the $\mathrm{K}=\mathrm{N}$ type concept was obtained in boyhood. In the $\mathrm{K} \neq \mathrm{A}, \mathrm{N}$ type, there were cases where new information $\mathrm{N}$ was accidentally created by combining known information from images. $\mathrm{K}=\mathrm{N}$ type that is a classification in which the concept $\mathrm{N}$ is derived from $\mathrm{K}$ was obtained in youth. However, there were fewer $\mathrm{K} \neq \mathrm{A}, \mathrm{N}$ type than in boyhood. From the $\mathrm{K}$-Type classification, it was found that in the process of growing up from boyhood to youth, creations that come up with the $\mathrm{K}=\mathrm{N}$ type concept are carried out.

As a result of the area in SD of each creation period and the $\mathrm{A} * \mathrm{~B}$ combination type classification, in the area of awareness, both boyhood and youth use their own knowledge and experience to solve problems like "knowledge and experience type". It turns out that we are looking for known information B. In the selection area, many function-added types and alternative types were seen in boyhood. In youth, many "knowledge and experience types" and "function-added types" were seen. From the results, it is considered that "knowledge and experience type" in the $\mathrm{A} * \mathrm{~B}$ combination type classification increased due to the increase in knowledge and experience due to the expansion of the living area as the child grew from boyhood to youth.

By classifying the creation period, it was able to see changes related to creation during the growth process from the area by $\mathrm{SD}$ and $\mathrm{A} * \mathrm{~B}$ combination type classification. In the awareness area, the method of searching for known information B did not change much, however in the selection area, the change could be seen as it grew. From this study, it confirmed the creation in boyhood and youth, confirmed the changes in the search method, etc. with growth, and found that there was no difference in the creative process performed. It was also confirmed that there is no difference in the creative process performed by working people regardless of changes in the growth period. It is thought that by providing creative education in boyhood and youth, it will be possible to create efficiently. 


\section{References}

[1] Basic ability to work in society; https://www.meti.go.jp/policy/kisoryoku/index.html.

[2] Ministry of Economy, Trade and Industry, Environmental, "Guide to Basic ability to work in society," Asahi Shimbun Publishing, 2010.

[3] Ministry of Economy, Trade and Industry, Environmental, "Development and evaluation of Basic ability to work in society," Kadokawa gakugei Publishing, 2008

[4] Three required forces, http://www.keidanren.or.jp/japanese/policy/2006/044/honbun.html.

[5] Koei Kishimoto and Mieko Watanabe" Textbooks to extend the ability to think", Nihon Keizai Shimbun, 2010.

[6] Shiuitiro Ono, Tsutomu Ohta, Kazutoshi Hatta, Toshio Sano, Yohei Hara and Yukiko Miyokawa "A Study of Creative Processes Based on the Relationship between the Clue Element and the Other Information Elements," International Journal of Japan Association for Management Systems, Vol.1, pp.13-18, September 2009.

[7] Makoto Takahashi, "The bible of creativity," Union of Japanese Scientists and Engineers, 2002.

[8] P. Bronson, A. Merryman : "The Creativity Crisis” Newsweek July 19, pp.24-29, 2010.

[9] Kenichi Yumino, "World creativity education,” Nakanishiya, 2005.

[10] Shinya Tsukamoto “ How to develop creativity,”Morikita, 2003. 